\title{
Assessing Progression of Keratoconus and Cross-linking Efficacy: The Belin ABCD Progression Display
}

\author{
${ }^{1}$ Michael W Belin, ${ }^{2}$ Jay J Meyer, ${ }^{3}$ Josh K Duncan, ${ }^{4}$ Rachel Gelman, ${ }^{5}$ Mark Borgstrom, ${ }^{6}$ Renato Ambrósio Jr
}

\begin{abstract}
Several methods have been described to both evaluate and document progression in keratoconus and to show efficacy of cross-linking, however, there are no consistent generally accepted parameters. Modern corneal tomography, including both anterior and posterior elevation and pachymetric data can be used to screen for ectatic progression, be employed to detect earlier change and additionally to show efficacy of new treatment modalities, such as crosslinking.

To describe specific quantitative values that can be used as progression and efficacy determinants, the normal noise measurements of the three parameters used in the ABCD keratoconus classification (corneal thickness at the thinnest point, anterior and posterior radius of curvature taken from the $3.0 \mathrm{~mm}$ optical zone centered on the thinnest point), were determined. Values were obtained from both a normal population and a known keratoconic population. The 80 and 95\% one-sided confidence intervals for all three parameters were surprisingly small, suggesting that they may perform well as progression and efficacy determinants.
\end{abstract}

Keywords: Collagen cross-linking, Ectatic disease, Keratoconus, Tomography, Topography.

How to cite this article: Belin MW, Meyer JJ, Duncan JK, Gelman R, Borgstrom M, Ambrósio Jr R. Assessing Progression of Keratoconus and Cross-linking Efficacy: The Belin ABCD Progression Display. Int J Kerat Ect Cor Dis 2017;6(1):1-10.

Source of support: Nil

Conflict of interest: None

\footnotetext{
${ }^{1}$ Professor, ${ }^{2}$ Senior Lecturer, ${ }^{3}$ Private Practitioner, ${ }^{4}$ Resident ${ }^{5}$ Statistical Consultant, ${ }^{6}$ Founder and Research Director

${ }^{1}$ Department of Ophthalmology and Vision Science, The University of Arizona, Tucson, Arizona, USA

${ }^{2}$ Department of Ophthalmology, The University of Auckland Auckland, New Zealand

${ }^{3}$ Department of Ophthalmology, Horizon Eye Specialists Phoenix, Arizona, USA

${ }^{4}$ Department of Ophthalmology, The University of Arizona Tucson Arizona, USA

${ }^{5}$ Department of Information Technology Services, The University of Arizona, Tucson, Arizona, USA

${ }^{6}$ Rio de Janeiro Corneal, Tomography and Biomechanics Study Group (Rio de Janeiro, Brazil); Associate Professor, Department of Ophthalmology, Federal University of São Paulo (São Paulo Brazil); Director of Cornea and Refractive Surgery, Instituto de Olhos Renato Ambrosio (Rio de Janeiro, Brazil)
}

Corresponding Author: Michael W Belin, 4232 West Summer Ranch Place, Marana, Arizona, USA, Phone: 0015185271933 e-mail: mwbelin@aol.com

\section{INTRODUCTION}

Keratoconus was first described in detail in 1854 as a chronic, non-inflammatory ectasia of the cornea. It is the most common primary ectasia and is characterized in its advanced state by corneal steepening, visual distortion, apical corneal thinning, and central corneal scarring. ${ }^{1-3}$ Corneal thinning typically occurs inferotemporal and central, although superior thinning has also been described. ${ }^{4}$ Keratoconus usually becomes apparent during the second decade of the life or earlier and typically progresses until the 4th decade of life, when progression slows or stabilizes. The corneal thinning induces irregular astigmatism, myopia, and conical protrusion, leading to mild to marked impairment in the quality of vision, and often has a significant impact on patient's quality of life. ${ }^{1}$ Keratoconus is relatively uncommon with a reported annual incidence of 2 per 100,000 and prevalence of 54.5 per 100,000, though rates vary greatly in different geographic regions. ${ }^{5-7}$ Keratoconus typically affects both eyes, although only one eye may be affected initially. ${ }^{8-9}$ The disease may be highly asymmetric ${ }^{8-9}$ and ocular symptoms and signs of keratoconus vary depending on disease severity. Early in the disease and in subclinical keratoconus, there may be minimal or no symptoms, whereas in advanced disease, there is significant distortion of vision accompanied by profound visual loss. ${ }^{10}$

Several classification systems for keratoconus have been proposed..$^{11-19}$ The Amsler-Krumeich (AK) system is amongst the oldest and still widely used. In the AK system, the severity of keratoconus is graded from stages I-IV using spectacle refraction, central keratometry, presence or absence of scarring, and central corneal thickness. ${ }^{20}$ The AK classification predated modern imaging technologies. Others have used this system with various modification and additions in an attempt to better diagnosis or characterize the severity of disease. ${ }^{21,22}$

\section{DOCUMENTING ECTATIC PROGRESSION}

In addition to the various classification and grading systems described in the literature, having a standardized method to document ectatic progression is equally important. The clinical decision to recommend treatments, such as corneal cross-linking is based largely on progressive ectasia. According to Global Consensus on Keratoconus and Ectatic Diseases (2015), there is no consistent or clear 
definition of ectasia progression, however, reports "ectasia progression" can be defined by a consistent change, with magnitude above the normal noise of the testing system, in at least two of the following parameters: Steepening of the anterior corneal surface, steepening of the posterior corneal surface, and thinning and/or an increase in the rate of corneal thickness change from the periphery to the thinnest point. The panel acknowledged that specific quantitative data were not yet available to further define progression, however, recommended consistency of testing methods and shorter intervals between testing and examination for younger individuals. ${ }^{23}$

Several methods have been described to both evaluate and document progression in keratoconus. More recent systems utilized serial topographic analysis alone to attempt to document disease progression. ${ }^{24-26}$ The most commonly used parameter being maximum anterior sagittal curvature (Kmax), which is also frequently applied with respect to determining cross-linking efficacy ${ }^{27,28}$ and progression of keratoconus postoperatively. ${ }^{29-31}$

A number of newly proposed systems use complex keratometric indices to describe progression. ${ }^{22,26}$ For example, Kanellopoulos et al looked at seven anterior surface pentacam-derived topometric indices: The index of surface variance (ISV), demonstrating corneal surface irregularity; index of vertical asymmetry (IVA) measuring curvature symmetry with respect to the horizontal meridian; keratoconus index, the ratio of mean radius value in the upper segment to mean radius value in the lower segment; central keratoconus index, the ratio of mean radius value in a peripheral ring to mean radius value in a central ring; index of height asymmetry, a calculation of height data symmetry between the superior and inferior areas with respect to the horizontal meridian; index of height decentration (IHD), representing the amount of decentration of elevation data in the vertical direction; and minimum radius of curvature, the smallest radius of sagittal corneal curvature, representing the maximum steepness of the cone. The authors concluded that the ISV and IHD, reflecting anterior surface variance across the cornea, may be the most sensitive and specific criteria in making an early diagnosis and assessing progression in keratoconus patients. ${ }^{22}$ In a longitudinal study, Li et al identified videokeratographic indices predictive for the development of keratoconus in the normal eye of unilateral keratoconus patients. Specifically, the authors found that higher keratoconus percentage index (KISA) and inferior-superior dioptric asymmetry value (I-S) are valuable in identifying patients at risk of progressing to keratoconus. ${ }^{26}$ The limitation of anterior surface parameters is their failure to depict early or subclinical disease and the likelihood for visual loss to already occur prior to documenting progression. ${ }^{32-36}$
The role of refractive parameters has also been used to detect ectatic progression. ${ }^{28,37-38}$ With Fourier harmonic analysis of videokeratography data, Oshika et $\mathrm{al}^{39}$ calculated the rate of change of different refractive components. Results showed that the rate of change was significantly positive for spherical component and higher order irregular astigmatism in keratoconic eyes vs normal eyes, suggesting that an increase in these parameters may indicate progression of keratoconus, even in the absence of apparent changes on a topographic map. Suzuki et $\mathrm{al}^{37}$ illustrated these same findings and added that eyes with apparent progression on color-coded maps demonstrated a strong correlation between the change rate per year of higher order irregularity, calculated by Fourier analysis and $\log$ MAR best spectacle-corrected visual acuity.

Sandali et $\mathrm{al}^{19}$ established anterior-segment optical coherence tomography (AS-OCT) as a grading system of severity in keratoconus based on structural changes. Specifically, stage I OCT was defined by thinner epithelium and stromal layers at the conus. Stage II OCT showed hyperreflective abnormalities at Bowman's layer, with an overlying thickened epithelium and variable amount of stromal opacities. Stage III OCT is a more advanced state of stage II. Stage IV OCT indicated stromal scarring involving the entire stromal thickness. And stage 5 OCT represents acute hydrops with cysts in the stroma in communication with the anterior chamber through a tear in Descemet's membrane. Fluid reaching the epithelium and inducing edema defines stage $5 \mathrm{a}$ and replacement of edema with complete corneal scarring defines stage $5 \mathrm{~b}$. These and a number of other parameters have been advocated to document progression. ${ }^{22,25,26,33-40}$ These include: Observing for change on the posterior elevation maps, change in best corrected distance visual acuity, reduction in apical corneal thickness, or an increase in anterior corneal asymmetry. However, to the best of our knowledge, none of these have been validated in peer-reviewed literature as methods to monitor progression. Additionally, these methods suffer from either being limited only to the anterior cornea or representing a small portion of the cornea, which may not properly depict changes in the ectatic region. Visual acuity methods are very variable ${ }^{36}$ and corneal thickness measurements are typically altered (thinned) after cross-linking, limiting its value to document treatment efficacy as well. ${ }^{41}$

It has been suggested that tomographic-derived pachymetry may be a more valuable method to document ectatic disease and follow progression. ${ }^{32,42}$ Furthermore, changes in posterior corneal curvature ${ }^{32-34}$ and corneal asymmetry have been shown to be additional methods of detecting early disease progression. ${ }^{22,43,44}$ 


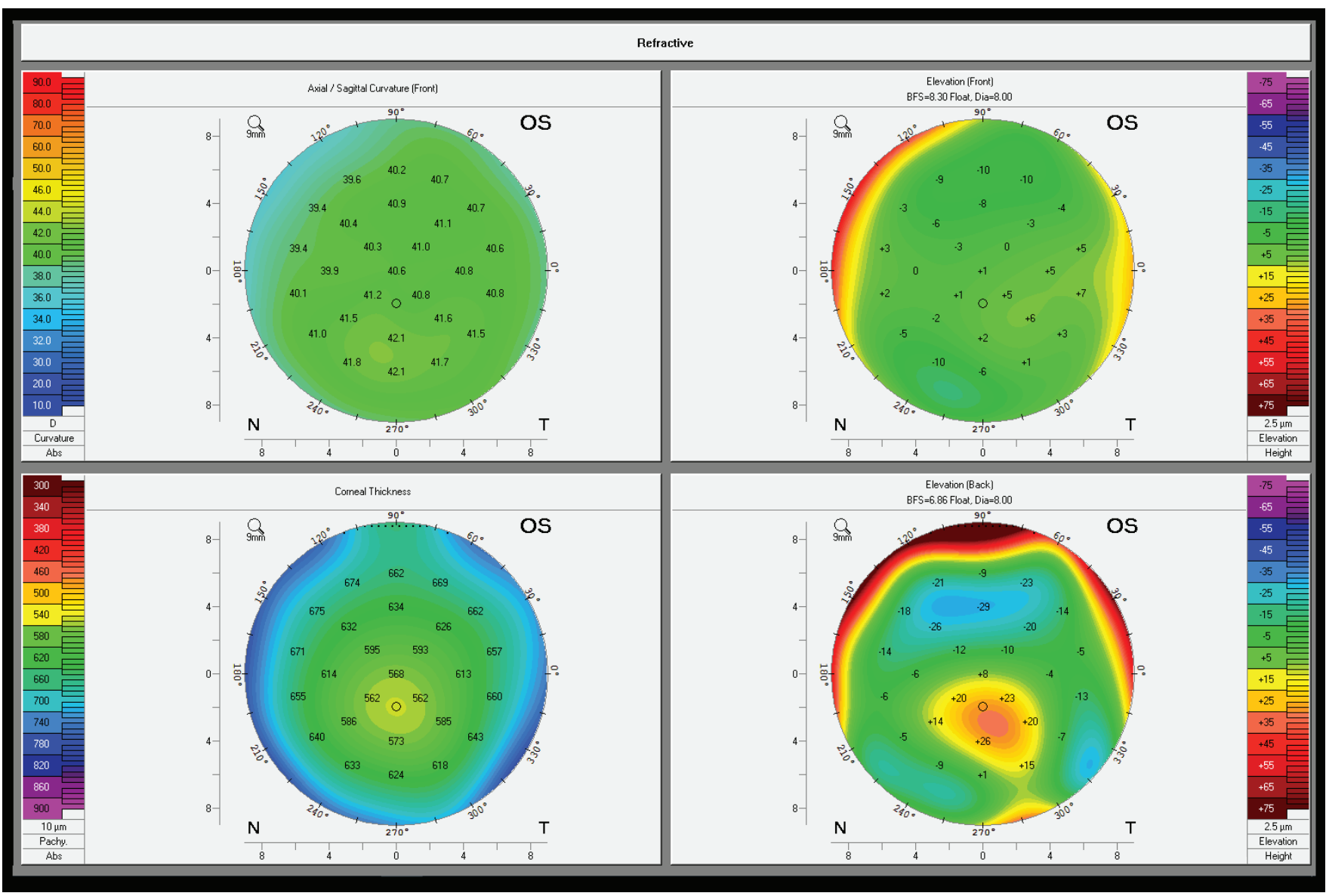

Fig. 1: Composite refractive map showing a normal anterior surface (Axial curvature upper left and anterior elevation upper right), a normal corneal thickness map (lower left) but a prominent posterior ectasia with an elevation value at the thinnest point in excess of 25 microns (lower right) (Oculus Pentacam)

\section{TOMOGRAPHIC-BASED ASSESSMENT OF ECTATIC PROGRESSION}

Modern corneal tomography (as opposed to topography) allows for the measurement of the anterior and posterior corneal surfaces as well as the anterior lens. ${ }^{45}$ With this information, both corneal thickness and anterior chamber depth can be computed. Early ectatic change is typically seen on the posterior corneal surface prior to anterior changes (Fig. 1). ${ }^{33}$

Additionally, alterations in the corneal thickness, such as a more rapid change from the thinne;st point to the periphery can be seen in early keratoconus even with normal appearing anterior and posterior maps (Fig. 2). ${ }^{42}$

The additional information available from anterior segment tomographic devices has led to the development of various refractive surgery screening programs. ${ }^{14,42,46-49}$ One such program is the Belin-Ambrosio enhanced ectrasia display (BAD). The BAD display (available on the Pentacam, OCULUS GmbH, Wetzlar, Germany) utilizes both anterior and posterior elevation data and pachymetric data to screen for ectatic change. ${ }^{50,51}$ It displays the elevation data against the commonly used bestfit-sphere (BFS) taken from the central $8.0 \mathrm{~mm}$ zone, but also uses a new reference surface called the "enhanced

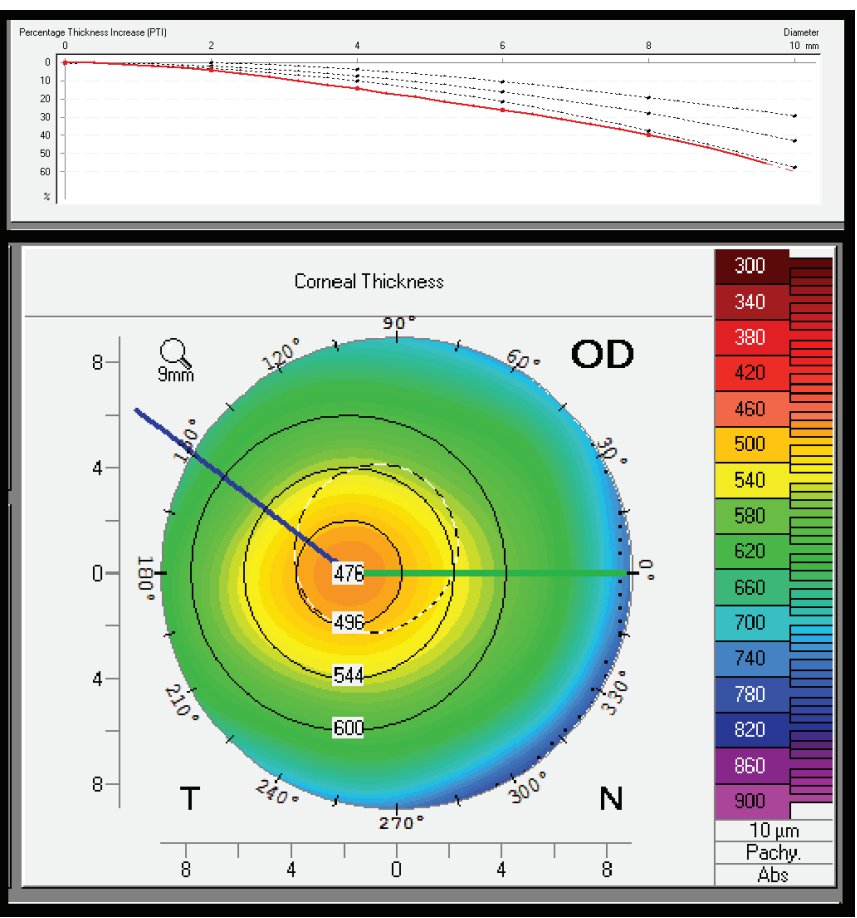

Fig. 2: Corneal thickness map and pachymetric progression graph [percentage thickness increase (PTI)]. The PTI tracing falls outside the normal range $(95 \%$ confidence interval) suggesting that this cornea is ectatic (abnormal) (Oculus Pentacam) 
reference surface (ERS)." While the BFS is both quantitatively and qualitatively useful, the clinician typically assumes that the reference surface closely approximates a "normal" cornea. This is actually not the case for ectatic corneas where the reference surface (typically a BFS taken from the central $8 \mathrm{~mm}$ zone) incorporates all data from the specified zone including normal and abnormal cornea. ${ }^{50,51}$ In the case of keratoconus or ectasia, the cone will have a steepening effect on the BFS. ${ }^{48,50,51}$ This steepened BFS will minimize the elevation difference between the apex of the cone and the BFS.

The concept behind the ERS is to generate a reference surface that more closely resembles the patient's own normal portion of the cornea as this will further magnify any existing ectatic pathology. To generate this new reference surface, a small diameter optical zone (exclusion zone) centered on the thinnest portion of the cornea is excluded from the $8.0 \mathrm{~mm}$ optical zone used for the standard BFS computation. The "enhanced BFS" is generated by utilizing all the valid elevation data from within the $8.0 \mathrm{~mm}$ central cornea, and outside the exclusion zone (Fig. 3).

The exact size of the exclusion zone varies between 3.0 to $4.0 \mathrm{~mm}$ based on a proprietary algorithm, but is typically $3.0 \mathrm{~mm}$ for keratoconic corneas. The resulting new reference surface, ERS, more closely approximates the more normal peripheral cornea and exaggerates any conical protrusion. The ERS was not only qualitatively useful in visualizing subtle or early ectatic change (Fig. 4), however, the elevation difference between a standard BFS and the ERS also proved to be highly significant quantitatively in separating normal eyes from those with ectatic change. ${ }^{51}$

The choice of the exclusion zone centered on the thinnest point was multifactorial. The size of the exclusion zone had to be large enough to have more global representation than single parameters, such as Kmax, however, if the area was too large, more "normal" cornea would be included. Extensive comparative testing resulted in the selection of a variable 3.0 to $4.0 \mathrm{~mm}$ exclusion zone.$^{50,51}$ The ERS works because the exclusion zone centered on the thinnest point incorporates the major ectatic region. Excluding this zone from the standard $8 \mathrm{~mm}$ BFS results in a reference surface that closely mimics the more normal portions of the cornea.

A similar concept has been used in a new keratoconus grading system. ${ }^{52,53}$ As opposed to excluding the 3.0 to $4.0 \mathrm{~mm}$ zone to normalize the reference surface, we employed the exclusion zone centered on the thinnest point as this area more globally represents the ectatic region than a single point parameter, such as Kmax or maximal elevation. The newly described ABCD keratoconus grading system uses the anterior and posterior radius of curvature taken from the $3.0 \mathrm{~mm}$ zone centered on the thinnest point (" $\mathrm{A}$ " for anterior, " $\mathrm{B}$ " for back surface) and the corneal thickness at the thinnest point (" $\mathrm{C}$ " for corneal thickness) as well as best-corrected distance visual acuity (" $\mathrm{D}$ " for distance visual acuity). This new classification/grading system has advantages over the older Amsler-Krumeich classification in that it recognizes the importance of the posterior corneal surface and each component (anterior, posterior, thickness, visual acuity) is individually graded. The "Belin $\mathrm{ABCD}$ " grading system has been incorporated in the OCULUS Pentacam software as part of the topometric/keratoconus grading display (Fig. 5).

The determination of progression is a major determinant in the decision of when and if to that a patient. Additionally, the same parameters can be used to determine crosslinking efficacy. As with the older grading systems, the problem with many of the commonly used progression parameters is that they were either limited to the anterior corneal surface, were measured on the corneal

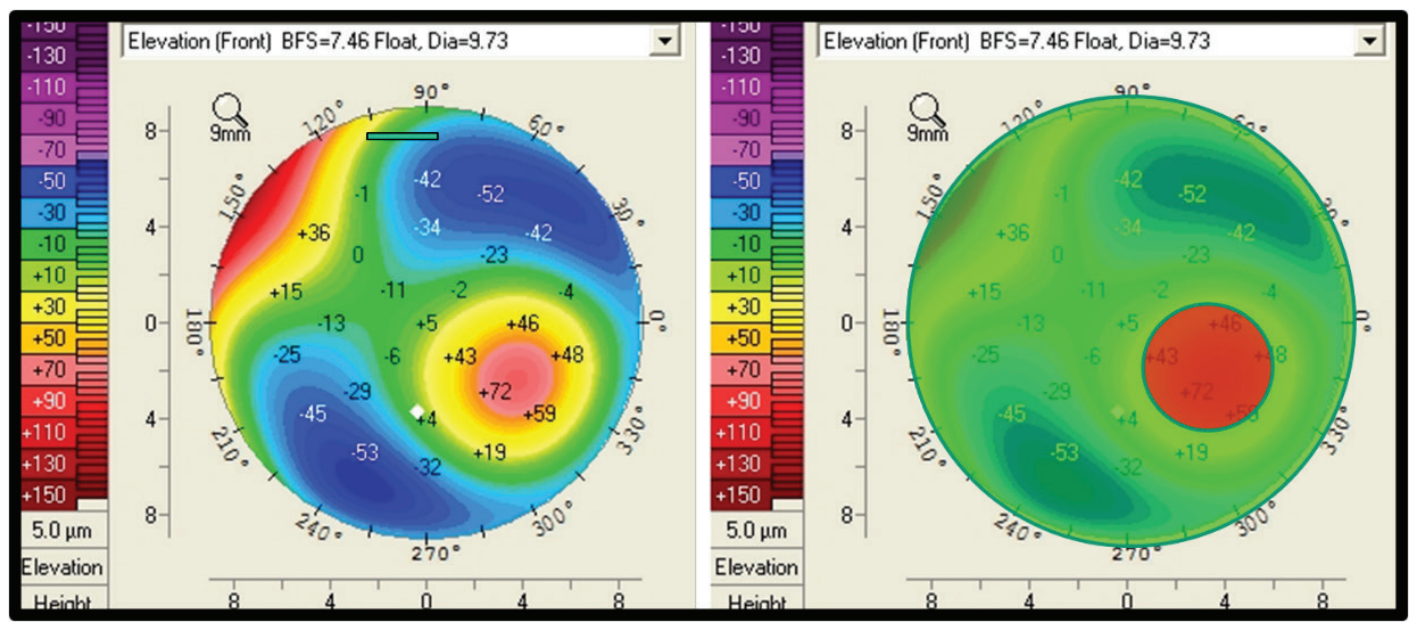

Fig. 3: Anterior elevation map (left) showing a prominent paracentral positive island indicative of keratoconus. The map of the right highlights in red the $3.0 \mathrm{~mm}$ exclusion zone centered on the thinnest point, i.e., removed from the calculation of the enhanced reference surface (Oculus Pentacam) 


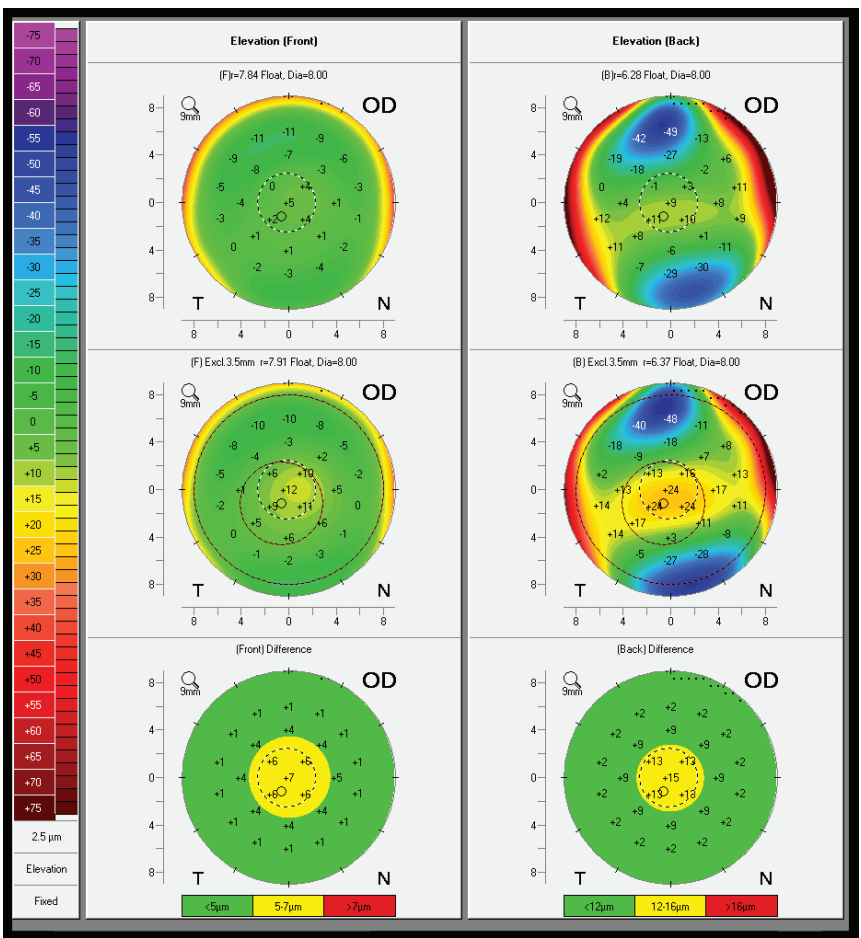

Fig. 4: Anterior and posterior elevation maps using standard BFS (upper left and right). The middle maps illustrate the same surfaces using the "enhanced reference surface" which accentuates the early ectatic regions. The lower display is the difference between the elevation values using a standard BFS and the "enhanced reference surface" (Oculus Pentacam)

Table 1: Prior parameters used to document progression

\begin{tabular}{|c|c|}
\hline Suggested parameter & Progression value \\
\hline $\begin{array}{l}\text { Spherical power, regular } \\
\text { astigmatism }\end{array}$ & Positive rate of change per year \\
\hline Kmax (steepest K) & $\geq 1.00 \mathrm{D}$ increase \\
\hline $\mathrm{Kmax}-\mathrm{Kmin}$ & $\geq 1.00 \mathrm{D}$ increase \\
\hline Kmean & $\geq 0.75 \mathrm{D}$ increase \\
\hline Pachymetry & $\begin{array}{l}\geq 2 \% \text { decrease in central } \\
\text { thickness }\end{array}$ \\
\hline $\begin{array}{l}\text { Back radius of the best fitting } \\
\text { contact lens }\end{array}$ & $0.1 \mathrm{~mm}$ or more decrease \\
\hline $\begin{array}{l}\text { Increase in the central } \mathrm{K} \\
\text { power }\end{array}$ & $\geq 1.50 \mathrm{D}$ increase from baseline \\
\hline Manifest cylinder & Increase of $\geq 1.00 \mathrm{D}$ in 24 months \\
\hline $\begin{array}{l}\text { Manifest spherical equivalent } \\
\text { change (MRSE) }\end{array}$ & $\geq 0.50 \mathrm{D}$ \\
\hline Index of surface variance & $\begin{array}{l}\text { Specific values for each } \mathrm{KCN} \\
\text { stage }\end{array}$ \\
\hline $\mathrm{IHA}$ & $\begin{array}{l}\text { Specific values for each KCN } \\
\text { stage }\end{array}$ \\
\hline
\end{tabular}

apex, or were single point parameters which often do not adequately reflect the cone (e.g., Kmax, apical pachymetry) (Table 1). Changes in the cone may occur with minimal changes in the apical cornea. This would be particularly true for decentered cones. Additionally, changes on the posterior cornea may occur without concurrent anterior changes and they may be posterior progression in spite of a normal anterior surface (subclinical keratoconus)
ABCD Grading System

Criteria A and ARC (3.Omm Zone)

Anterior Radius of Curvature. Average curvature in the $30 \mathrm{~mm}$ zone centered on the thinnest location of the cornea.

Criteria B and PRC [3.0 $\mathrm{mm}$ Zone]

Posterior Radius of Curvature in the $3.0 \mathrm{~mm}$ zone. Average curvature in the $3.0 \mathrm{~mm}$ zone centered

on the thinnest lacation of the comea.

Criteria $\mathrm{C}$ and Thinnest Pachymetry

Thinnest pachymety in $\mu \mathrm{m}$

Criteria $\mathrm{D}$ and $\mathrm{DCV} \mathrm{A}$

"Distance Best Corrected Visual Acuity"

DCVA is not generated by the Pentacam software. It should be input manually by clicking left mouse into the corresponding field.

The input value will be saved to the examination.

Whole number stages are rounded down from the number with decimal place.

\begin{tabular}{|c|c|c|c|c|c|}
\hline $\begin{array}{c}\text { ABCD } \\
\text { Criteria }\end{array}$ & $A$ & B & C & D & \\
\hline & $\begin{array}{c}\text { ARC } \\
\text { (3 mm Zone) }\end{array}$ & $\begin{array}{c}\text { PRC } \\
\text { (3 mm Zone) }\end{array}$ & $\begin{array}{l}\text { Thinnest } \\
\text { Pach um }\end{array}$ & BDVA & Scarring \\
\hline$\underset{0}{\text { STAGE }}$ & $\begin{array}{c}>7.25 \mathrm{~mm} \\
(<46.5 \mathrm{D})\end{array}$ & $\begin{array}{c}>5.90 \mathrm{~mm} \\
(<57.25 \mathrm{D})\end{array}$ & $>490 \mathrm{um}$ & $\begin{array}{c}=20 / 20 \\
(=1.0)\end{array}$ & - \\
\hline$\underset{\text { I }}{\text { STAGE }}$ & $\begin{array}{c}>7.05 \mathrm{~mm} \\
(<48.0 \mathrm{D})\end{array}$ & $\begin{array}{c}>5.70 \mathrm{~mm} \\
(<59.25 \mathrm{D})\end{array}$ & $>450 \mathrm{um}$ & $\begin{array}{c}<20 / 20 \\
(<1.0)\end{array}$ &,,-+++ \\
\hline $\begin{array}{c}\text { STAGE } \\
\text { II }\end{array}$ & $\begin{array}{c}>6.35 \mathrm{~mm} \\
(<53.0 \mathrm{D})\end{array}$ & $\begin{array}{c}>5.15 \mathrm{~mm} \\
(<65.5 \mathrm{D})\end{array}$ & $>400 \mathrm{um}$ & $\begin{array}{c}<20 / 40 \\
(<0.5)\end{array}$ &,,-+++ \\
\hline $\begin{array}{c}\text { STAGE } \\
\text { III }\end{array}$ & $\begin{array}{c}> \\
(<55.15 \mathrm{~mm})\end{array}$ & $\begin{array}{c}>4.95 \mathrm{~mm} \\
(<68.5 \mathrm{D})\end{array}$ & $>300 \mathrm{um}$ & $\begin{aligned}<20 / 100 & 20.2)\end{aligned}$ &,,-+++ \\
\hline$\underset{\text { IV }}{\text { STAGE }}$ & $\begin{array}{c}<6.15 \mathrm{~mm} \\
(>55.0 \mathrm{D})\end{array}$ & $\begin{array}{c}<4.95 \mathrm{~mm} \\
(>68.5 \mathrm{D})\end{array}$ & Im & $\begin{array}{c}<20 / 400 \\
(<0.05)\end{array}$ & - \\
\hline
\end{tabular}

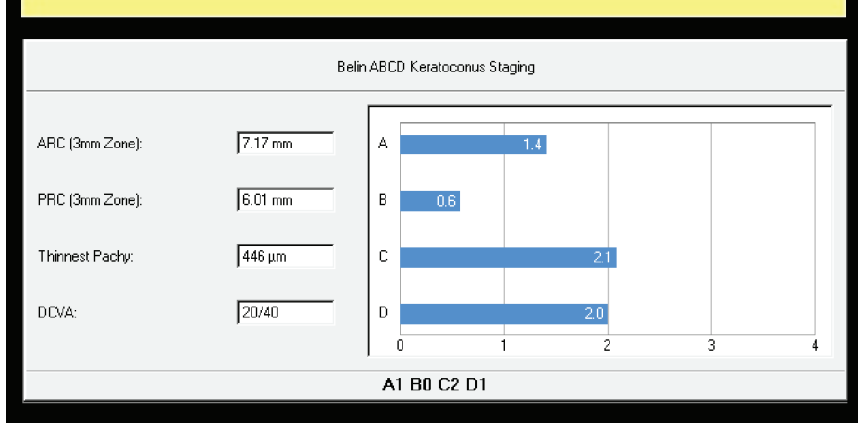

Fig. 5: The ABCD grading/classification system. The upper portion (available as a drop-down menu) explains the values used in the classification. The lower portion is the classification display. Values for anterior and posterior radius of curvature from the 3.0 $\mathrm{mm}$ zone centered on the thinnest point and thinnest pachymetry are listed. Visual acuity is operator entered. The four ABCD values are graphically display and the final classification is shown on the bottom (Oculus Pentacam)

(Fig. 6). Progressive posterior ectasia will be accompanied by further corneal thinning, however, this may not be detected by only taking measurements at the corneal apex.

Measuring corneal thickness change at the thinnest point should be a more sensitive indicator of progression than apical pachymetry. Changes to the anterior and posterior BFS taken from the $3.0 \mathrm{~mm}$ zone centered on the thinnest point should also be a more sensitive indicator of cone progression. Because all three parameters are centered on the thinnest point (surrogate for center of the cone) and limited to the conical region, they should reflect change earlier than more global parameters (e.g., IHD, ISV) and/or parameters measured from the corneal apex. To utilize these parameters as indicators of progression, the normal measurement noise needs to be known. This allows us to separate true change 


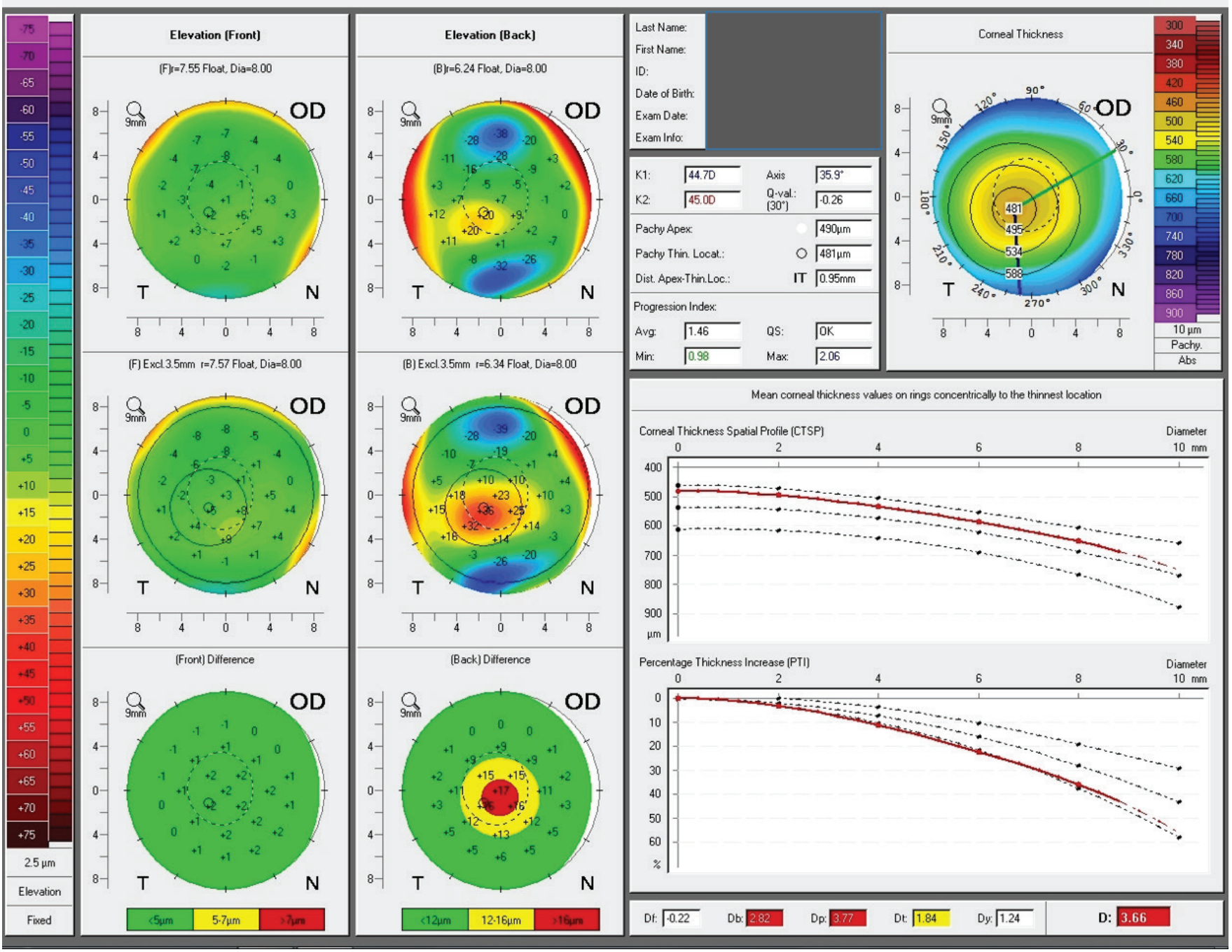

Fig. 6: Belin/Ambrosio enhanced ectasia display (BAD) illustrating a case of subclinical keratoconus. The posterior elevation maps show a very prominent posterior ectasia and the PTI graph is also abnormal. The final "D" is 3.66 which is highly abnormal in spite of a normal anterior surface and excellent visual acuity (Oculus Pentacam)

from measurement variance or noise. While numerous articles have been written on normal values generated by Scheimpflug imaging or OCT, ${ }^{48,49,54,55}$ anterior and posterior curvature from the $3.0 \mathrm{~mm}$ zone centered on the thinnest point are newly developed parameters with only recent published data. ${ }^{56}$

Measurement noise of the three parameters [corneal thickness at the thinnest point and anterior and posterior radius of curvature (ARC, PRC) taken from the $3.0 \mathrm{~mm}$ optical zone centered on the thinnest point], was determined in both normal and keratoconic populations as it is well known that measurements in distorted corneas are more variable. We choose to sample a normal population because of the clinical importance in determining progression in borderline, subclinical cases or in early pediatric cases. Here, the normal patient variation is probably more applicable and more closely approximates very early disease than values determined from known cases of keratoconus. There are many surgeons who promote cross-linking in children at the first sign of ectatic change. Here, using parameters deduced from keratoconus patients would probably delay treatment.

To determine the suitability of the above three parameters as potential progression determinants, both a pooled variance estimate and a one-sided confidence interval were computed using both Statistical Package for the Social Sciences version 23 (IBM Corp., Armonk, New York) and STATA 13 (StataCorp LP, College Station, TX). A onesided confidence interval was chosen because progression is indicated by thinning and/or steepening of the anterior and/or posterior corneal surfaces. For each of these parameters (corneal thickness, ARC, PRC), a decrease would be indicative of progression. Both the 95 and $80 \%$ confidence intervals were determined since the risk/benefit ratio for medical/surgical intervention would vary based on the age of the patient, family history, condition of the other 
eye, etc., and both the physician and patient's decisions could vary based on a multitude of factors including the risk aversion of the patient and/or surgeon. The standard deviation and one-sided confidence intervals for the normal database were previously reported. ${ }^{56}$

The keratoconic data were generated by examining three repetitive exams from known keratoconus patients taken on the same day at the University of Auckland, Department of Ophthalmology (Auckland, New Zealand). All patients were fully removed from the Pentacam between exams. Initial exams were reviewed by a fellowship trained corneal specialist (JJM) for suitability. Data files (U12 files) were then exported and analyzed (MB, MWB). All study patients had bilateral disease and one eye was randomly selected for analysis. A total of 252 exams from 84 patients were utilized to generate measurement standard deviations and 80 and 95\% one-sided confidence intervals (Table 2).

\section{BELIN ABCD PROGRESSION DISPLAY}

The Belin $A B C D$ progression display was designed to graphically display the $\mathrm{ABCD}$ parameters over time with their associated 80 and 95\% confidence intervals for both the normal (green broken line and solid green respectively) and keratoconic database (red broken line and red solid respectively). The baseline exam (BE) can be marked and the time of treatment (e.g., cross-linking)
Table 2: One sided confidence intervals for normal and keratoconic population

\begin{tabular}{llll}
\hline & Standard dev & $95 \% \mathrm{Cl}$ 1-tail & $80 \% \mathrm{Cl}$ 1-tail \\
\hline $\begin{array}{l}\text { Keratoconus ARC } \\
(\mathrm{n}=252)\end{array}$ & $0.062 \mathrm{~mm}$ & $0.102 \mathrm{~mm}$ & $0.052 \mathrm{~mm}$ \\
$\begin{array}{l}\text { Normal ARC } \\
(\mathrm{n}=135)\end{array}$ & $0.015 \mathrm{~mm}$ & $0.024 \mathrm{~mm}$ & $0.012 \mathrm{~mm}$ \\
Keratoconus PRC & $0.062 \mathrm{~mm}$ & $0.102 \mathrm{~mm}$ & $0.052 \mathrm{~mm}$ \\
Normal PRC & $0.050 \mathrm{~mm}$ & $0.083 \mathrm{~mm}$ & $0.042 \mathrm{~mm}$ \\
$\begin{array}{l}\text { Keratoconus min } \\
\text { pach }\end{array}$ & $6.03 \mathrm{um}$ & $9.92 \mathrm{um}$ & $5.07 \mathrm{um}$ \\
Normal min pach & $4.79 \mathrm{um}$ & $7.88 \mathrm{um}$ & $4.03 \mathrm{um}$ \\
\hline
\end{tabular}

can be noted and shown by the black and white checkered line. Up to eight exams can be displayed and are automatically loaded by the Pentacam (Graph 1). Each parameter can then be examined over time and compared to the individual confidence intervals (" $\mathrm{D}$ " distance spectacle visual acuity does not have confidence bars). Furthermore, treatment efficacy can be evaluated by examining the postoperative data in a similar fashion. In addition to the graphical display of the primary $\mathrm{ABCD}$ parameters, ten additional tomographic/topographic parameters (BAD " $\mathrm{D}$ ", progression index average, Ambrosio relational thickness maximum, Kmax, $Q$ value $6.0 \mathrm{~mm}$ zone front, $Q$ value $6.0 \mathrm{~mm}$ zone back, ISV, IVA, IHD, and the $\mathrm{ABCD}$ classification) are shown in tabular form.

Graph 1 is illustrative of the features of the display. Five exams are shown, with the first two documenting

OCULUS - PENTACAM Belin ABCD Progressions Display

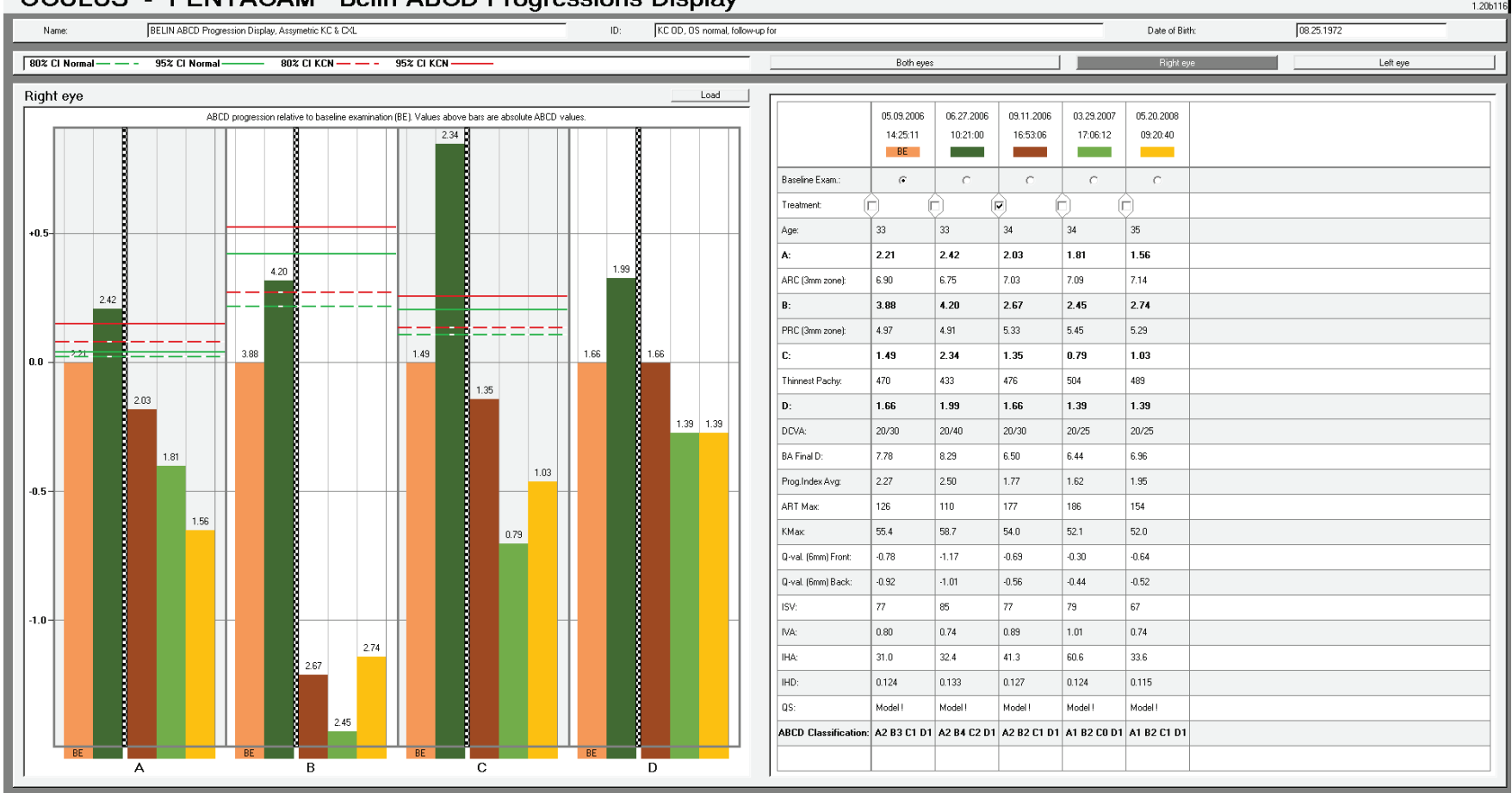

Graph 1: Belin ABCD progression display. The ABCD parameters are graphically displayed over time. The first two exams from a patient with known keratoconus show progression of the anterior surface and thinning of the cornea beyond the $95 \%$ confidence interval (keratoconic database) and of the posterior surface above the $80 \%$ confidence interval. The black and white checkered line when cross-linking was performed with subsequent improvement posttreatment (Oculus Pentacam) 
OCULUS - PENTACAM Belin ABCD Progressions Display

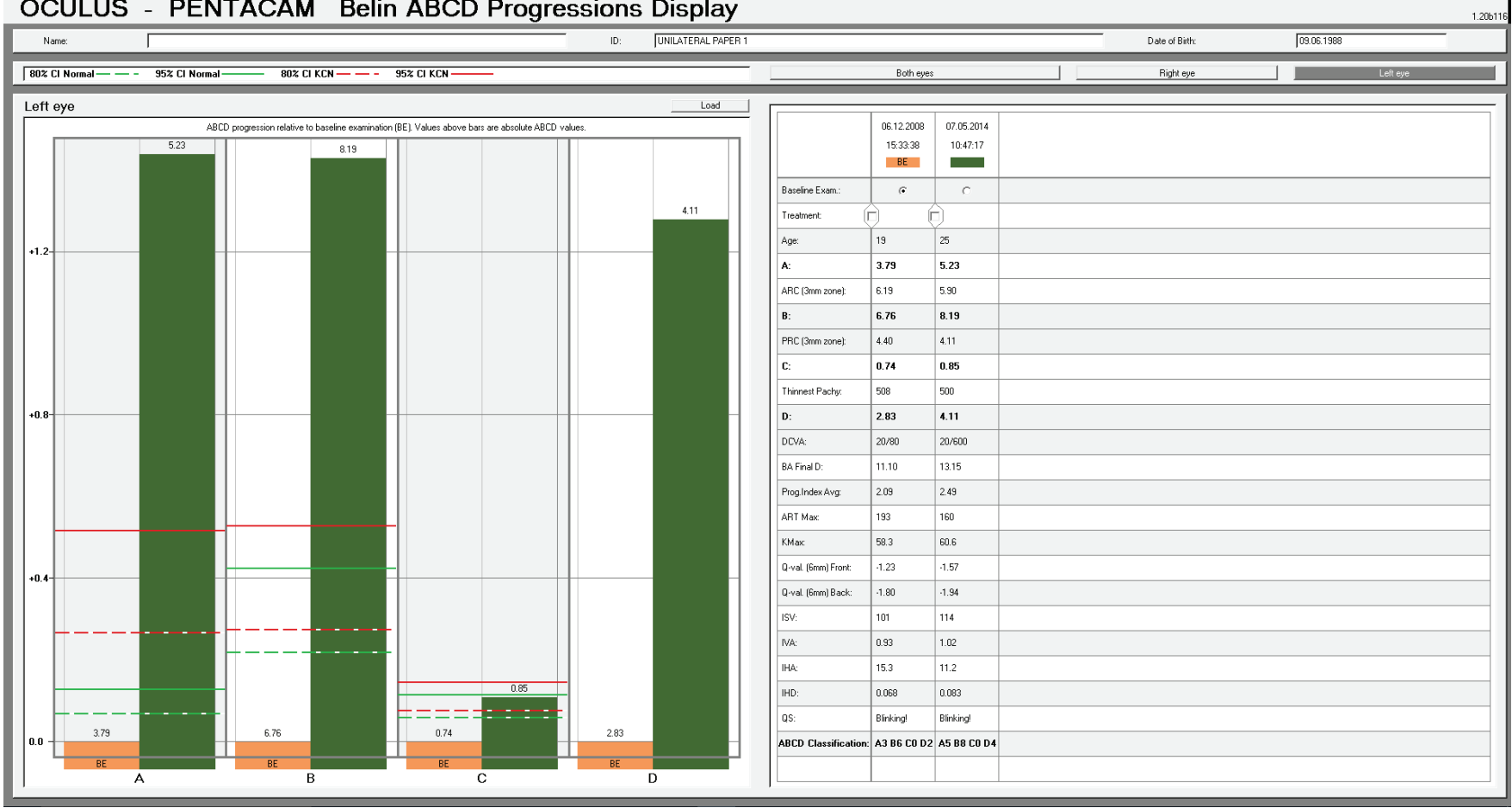

Graph 2: Belin ABCD progression display. A patient with known keratoconus over a 6-year interval demonstrating marked progression of the anterior and posterior surface and moderate corneal thinning associated with a further decrease in visual acuity (Oculus Pentacam)

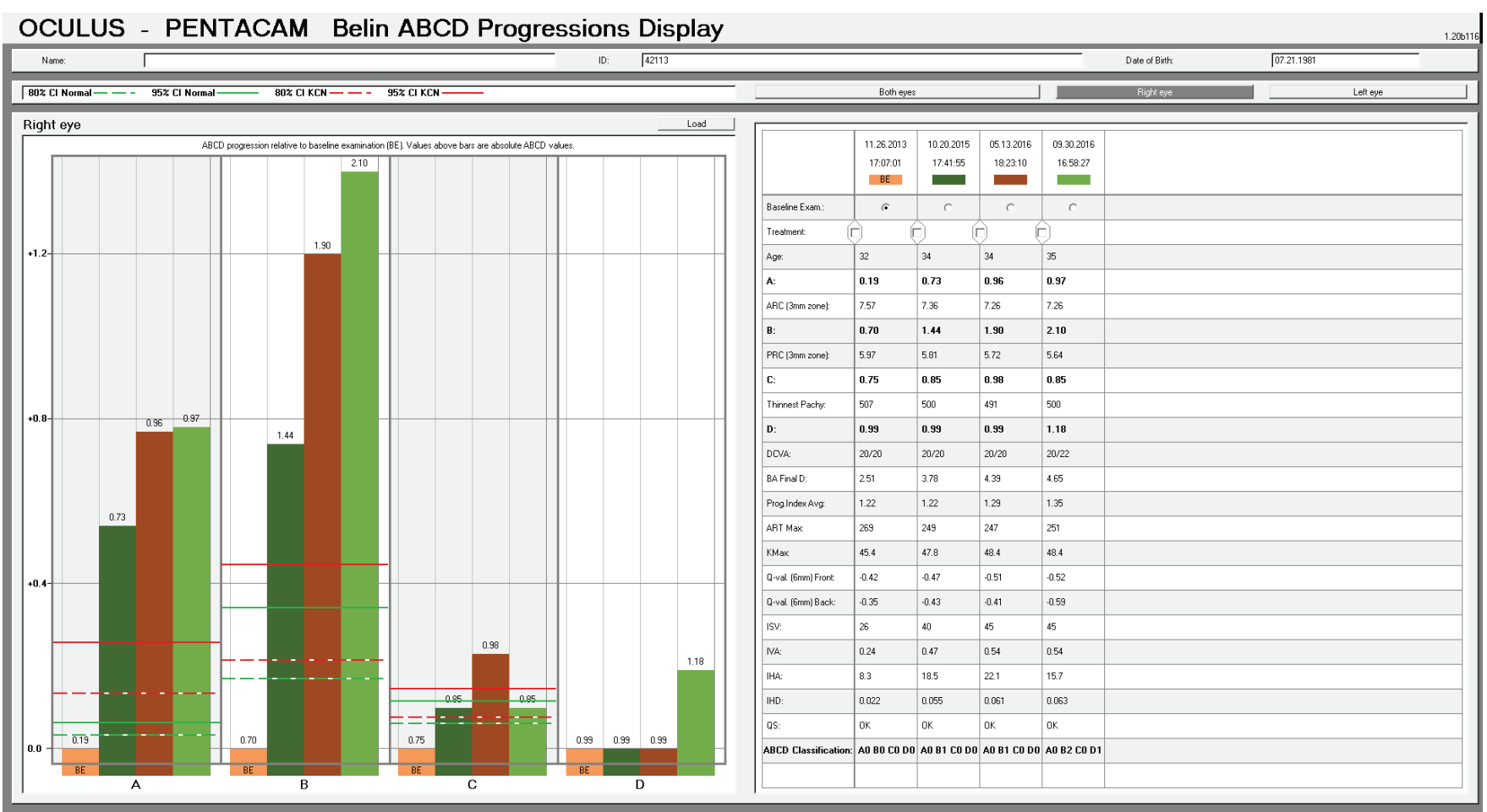

Graph 3: Belin ABCD progression display. The "normal" right eye of a patient thought to have unilateral keratoconus. Four exams are displayed over a 2-year 10-month period. It was only at the last exam that the patient reported any subjective findings of mild visual distortion, though the progression display shows significant change prior to a loss of visual function (Oculus Pentacam)

significant change and the subsequent three post crosslinking exams demonstrating the efficacy of the treatment. Graph 2 shows two exams over a six-year interval from a known untreated keratoconus patient with marked progression of both the anterior and posterior ectatic regions, minimal progressive thinning, and a marked loss in visual acuity. Graph 3 documents the clinical utility of the progression display. This is the "normal" appearing right eye of a patient with known keratoconus in the left eye. Since the patient was asymptomatic and in 
their mid-thirties, the physician was comfortable offering no treatment. The ABCD progression display, despite an A0B0C0D0 classification, documents progressive change suggesting that treatment may be warranted or minimally closer observation.

\section{CONCLUSION}

As noted earlier, according to Global Consensus on Keratoconus and Ectatic Diseases (2015), there is no consistent or clear definition of ectasia progression. ${ }^{23}$ The panel defined progression by a consistent change in at least two of the following parameters: Steepening of the anterior corneal surface, steepening of the posterior corneal surface, and thinning and/or thinning or changes in the pachymetric rate of change. The panel, however, acknowledged that specific quantitative data to define progression is lacking. ${ }^{23}$ Our goal was to evaluate the "ABCD" parameters, determine the quantitative values and to access their suitability as progression determinants. Both the 95 and $80 \%$ one-sided confidence intervals for all three parameters were surprisingly small, suggesting that they may perform well as progression determinants. Measurements were performed both on normal patients and known keratoconic patients. Normal subjects were chosen as these values probably better reflect early disease than values generated from known keratoconus patients. These parameters were graphically displayed with their accompanying confidence intervals in the Belin ABCD progression display currently available on the OCULUS Pentacam. These parameters were partially chosen because they would be simple to incorporate in any tomographic imaging system. The use of the progression display in addition to the ABCD grading system should offer an improved method of classifying and grading keratoconus and assist in documenting progression of disease.

\section{REFERENCES}

1. Nottingham J. Practical observations on conical cornea: and on the short sight, and other defects of vision connected with it. London: J Churchill; 1854.

2. Rabinowitz YS. Keratoconus. Surv Ophthalmol 1998 JanFeb;42(4):297-319.

3. Krachmer JH, Feder RS, Belin MW. Keratoconus and related noninflammatory corneal thinning disorders. Surv Ophthalmol 1984 Jan-Feb;28(4):293-322.

4. Weed KH, McGhee CN, Mac Ewen CJ. Atypical unilateral superior keratoconus in young males. Cont Lens Anterior Eye 2005 Dec;28(4):177-179.

5. Gorskova EN, Sevost'ianov EN. [Epidemiology of keratoconus in the Urals]. Vestn Oftalmol 1998 Jul-Aug;114(4):38-40.

6. Jonas JB, Nangia V, Matin A, Kulkarni M, Bhojwani K. Prevalence and associations of keratoconus in rural Maharashtra in central India: the central India eye and medical study. Am J Ophthalmol 2009 Nov;148(5):760-765.
7. Kennedy RH, Bourne WM, Dyer JA. A 48-year clinical and epidemiologic study of keratoconus. Am J Ophthalmol 1986 Mar 15;101(3):267-273

8. Lee LR, Hirst LW, Readshaw G. Clinical detection of unilateral keratoconus. Aust N Z J Ophthalmol 1995 May;23(2):129-133.

9. Rabinowitz YS, Nesburn AB, McDonnell PJ. Videokeratography of the fellow eye in unilateral keratoconus. Ophthalmology 1993 Feb;100(2):181-186.

10. Belin MW, Kim JT, Zloty P, Ambrósio R Jr. Simplified nomenclature for describing keratoconus. Int J Keratoco Ectatic Corneal Dis 2012 Jan-Apr;1(1):31-35.

11. Perry HD, Buxton JN, Fine BS. Round and oval cones in keratoconus. Ophthalmology 1980 Sep;87(9):905-909.

12. Krumeich JH, Daniel J, Knülle A. Live-epikeratophakia for keratoconus. J Cataract Refract Surg 1998 Apr;24(4): 456-463.

13. Rabinowitz YS, Rasheed K. KISA\% index: a quantitative videokeratography algorithm embodying minimal topographic criteria for diagnosing keratoconus. J Cataract Refract Surg 1999 Oct;25(10):1327-1335.

14. Maeda N, Klyce SD, Smolek MK, Thompson HW. Automated keratoconus screening with corneal topography analysis. Invest Ophthalmol Vis Sci 1994 May;35(6):2749-57.

15. Alió JL, Shabayek MH. Corneal higher order aberrations: a method to grade keratoconus. J Refract Surg 2006 Jun;22(6):539-545.

16. McMahon TT, Szczotka-Flynn L, Barr JT, Anderson RJ, Slaughter ME, Lass JH, Iyengar SK; CLEK Study Group. A new method for grading the severity of keratoconus: the keratoconus severity score (KSS). Cornea 2006 Aug;25(7): 794-800.

17. Mahmoud AM,RobertsCJ,LembachRG, TwaMD,HerderickEE, McMahon TT; CLEK Study Group. CLMI: the cone location and magnitude index. Cornea 2008 May;27(4):480-487.

18. Li X, Yang H, Rabinowitz YS. Keratoconus: classification scheme based on videokeratography and clinical signs. J Cataract Refract Surg 2009 Sep;35(9):1597-1603.

19. Sandali $\mathrm{O}$, El Sanharawi M, Temstet C, Hamiche T, Galan A, Ghouali W, Goemaere I, Basli E, Borderie V. Fourier-domain optical coherence tomography imaging in keratoconus: acorneal structural classification. Ophthalmology. 2013 Dec;120(12):2403-2412.

20. Amsler M. Keratoconeclassiqueetkeratoconefruste, arguments unitaires. Ophtalmologica 1946;111:96-101.

21. Kamiya K, Ishii R, Shimizu K, Igarashi A. Evaluation of corneal elevation, pachymetry and keratometry in keratoconic eyes with respect to the stage of Amsler-Krumeich classification. Br J Ophthalmol 2014 Apr;98(4):459-463.

22. Kanellopoulos AJ, Asimellis G. Revisiting keratoconus diagnosis and progression classification based on evaluation of corneal asymmetry indices, derived from Scheimpflug imaging in keratoconic and suspect cases. Clin Ophthalmol 2013;7:1539-1548.

23. Gomes JA, Tan D, Rapuano CJ, Belin MW, Ambrósio R Jr, Guell JL, Malecaze F, Nishida K. Global consensus on keratoconus and ectatic disease. Cornea 2015 Apr;34(4):359-369.

24. Maguire LJ, Lowry JC. Identifying progression of subclinical keratoconus by serial topography analysis. Am J Ophthalmol 1991 Jul;112(1):41-45.

25. Choi JA, Kim MS. Progression of keratoconus by longitudinal assessment with corneal topography. Invest Ophthalmol Vis Sci 2012 Feb;53(2):927-935. 
26. Li X, Yang H, Rabinowitz YS. Longitudinal study of keratoconus progression. Exp Eye Res 2007 Oct;85(4):502-507.

27. Wittig-Silva $\mathrm{C}$, Chan E, Islam FM, Wu T, Whiting $\mathrm{M}$, Snibson GR. A randomized, controlled trial of corneal collagen cross-linking in progressive keratoconus: three-year results. Ophthalmology 2014 Apr;121(4):812-821.

28. O'Brart DP, Chan E, Samaras K, Patel P,Shah SP. A randomized, prospective study to investigate the efficacy of riboflavin/ ultraviolet A (370 nm) corneal collagen cross-linking to halt progression of keratoconus. Br J Ophthalmol 2011 Nov;95(11): 1519-1524.

29. Sykakis E, Karim R, Evans JR, Bunce C, Amissah-Arthur KN, Patwary S, McDonnell PJ, Hamada S. Corneal collagen crosslinking for treating keratoconus. Cochrane Database Syst Rev 2015 Mar 24;(3):CD010621.

30. Epstein RL, Chiu YL, Epstein GL. Pentacam HR criteria for curvature change in keratoconus and postoperative LASIK ectasia. J Refract Surg 2012 Dec;28(12):890-894.

31. Barbara R, Castillo JH, Hanna R, Berkowitz E, Tiosano B, Barbara A. Keratoconus expert meeting, London, 2014. J Kerat Ect Cor Dis 2014;3(3):141-158.

32. Mahmoud AM, Nuñez MX, Blanco C, Koch DD, Wang L, Weikert MP, Frueh BE, Tappeiner C, Twa MD, Roberts CJ. Expanding the cone location and magnitude index to include corneal thickness and posterior surface information for the detection of keratoconus. Am J Ophthalmol 2013 Dec;156(6):1102-1111.

33. de Sanctis U, Loiacono C, Richiardi L, Turco D, Mutani B, Grignolo FM. Sensitivity and specificity of posterior corneal elevation measured by Pentacam in discriminating keratoconus/subclinical keratoconus. Ophthalmology 2008 Sep;115(9):1534-1539.

34. Tomidokoro A, Oshika T, Amano S, Higaki S, Maeda N, Miyata K. Changes in anterior and posterior corneal curvatures in keratoconus. Ophthalmology 2000 Jul;107(7): 1328-1332.

35. Lopes BT, Ramos IC, Faria-CorreiaF, Luz A, de Freitas Valbon B, Belin MW, Ambrósio R Jr. Correlation of topometric and tomographic indices with visual acuity in patients with keratoconus. J Kerat Ect Cor Dis 2012;1(3):167-172.

36. Kanellopoulos AJ, Moustou V, Asimellis G. Evaluation of visual acuity, pachymetry and anterior-surface irregularity in keratoconus and crosslinking intervention follow-up in 737 cases. J Kerat Ect Cor Dis 2013;2(3):95-103.

37. Suzuki M, Amano S, Honda N, Usui T, Yamagami S, Oshika T. Longitudinal changes in corneal irregular astigmatism and visual acuity in eyes with keratoconus. Jpn J Ophthalmol 2007 Jul-Aug;51(4):265-269.

38. Chatzis N, Hafezi F. Progression of keratoconus and efficacy of pediatric [corrected] corneal collagen cross-linking in children and adolescents. J Refract Surg 2012 Nov;28(11): 753-758.

39. Oshika T, Tanabe T, Tomidokoro A, Amano S. Progression of keratoconus assessed by fourier analysis of videokeratography data. Ophthalmology 2002 Feb;109(2):339-342.

40. Hersh PS, Greenstein SA, Fry KL. Corneal collagen crosslinking for keratoconus and corneal ectasia: one-year results. J Cataract Refract Surg 2011 Jan;37(1):149-160.
41. Sefic Kasumovic S, Racic-Sakovic A, Kasumovic A, Pavljasevic S, Duric-Colic B, Cabric E, Mavija M, Lepara O, Jankov M. Assessment of the tomographic values in keratoconic eyes after collagen crosslinking procedure. Med Arch 2015 Apr;69(2):91-94.

42. Ambrósio R Jr, Caiado AL, Guerra FP, Louzada R, Roy AS, Luz A, Dupps WJ, Belin MW. Novel pachymetric parameters based on corneal tomography for diagnosing keratoconus. J Refract Surg 2011 Oct;27(10):753-758.

43. Kanellopoulos AJ, Asimellis G. OCT corneal epithelial topographic asymmetry as a sensitive diagnostic tool for early and advancing keratoconus. Clin Ophthalmol 2014 Nov;8: 2277-2287.

44. Khachikian SS, Belin MW, Ciolino JB. Intrasubject corneal thickness asymmetry. J Refract Surg 2008 Jun;24(6):606-609.

45. Belin MW, Khachikian SS. An introduction to understanding elevation-based topography: how elevation data are displayed - a review. Clin Exp Ophthalmol 2009 Jan;37(1):14-29.

46. Fam HB, Lim KL. Corneal elevation indices in normal and keratoconic eyes. J Cataract Refract Surg 2006 Aug;32(8): 1281-1287.

47. Chastang PJ, Borderie VM, Carvajal-Gonzalez S, Rostène W, Laroche L. Automated keratoconus detection using the EyeSys videokeratoscope. J Cataract Refract Surg 2000 May;26(5):675-683.

48. Belin MW, Ambrósio R. Scheimpflug imaging for keratoconus and ectatic disease. Indian J Ophthalmol 2013 Aug;61(8): 401-406.

49. Belin MW, Villavicencio OF, Ambrosio RR Jr. Tomographic parameters for the detection of keratoconus: suggestions for screening and treatment parameters. Eye Contact Lens 2014 Nov;40(6):326-330.

50. Villavicencio OF, Gilani F, Henriquez MA, Izquierdo L Jr, Ambrósio R Jr, Belin MW. Independent population validation of the Belin/Ambrosio enhanced ectasia display: implications for keratoconus studies and screening. Int J Kerat Ect Cor Dis 2014;3(1):1-8.

51. Belin MW, Khachikian SS, Ambrósio R Jr, Salomão M. Keratoconus/ectasia detection with the oculus pentacam: Belin/ Ambrósio enhanced ectasia display. Highlights Ophthalmol 2007;35:5-12.

52. Belin MW, Duncan JK, Ambrósio R Jr, Gomes JAP. A new tomographic method of staging/classifying keratoconus: the ABCD grading system. Int J Kerat Ect Cor Dis 2015;4(3):55-63.

53. Belin MW, Duncan JK.Keratoconus:the ABCD grading system. Klin Monbl Augenheilkd 2016 Jan;233(6):701-707.

54. Feng MT, Belin MW, Ambrósio R Jr, Grewal SP, Yan W, Shaheen MS, Jordon CA, McGhee C, Maeda N, Neuhann TH, et al. International values of corneal elevation in normal subjects by rotating Scheimpflug camera. J Cataract Refract Surg 2011 Oct;37(10):1817-1821.

55. Gilani F, Cortese M, Ambrósio RR Jr, Lopes B, Ramos I, Harvey EM, Belin MW. Comprehensive anterior segment normal values generated by rotating Scheimpflug tomography. J Cataract Refract Surg 2013 Nov;39(11):1707-1712.

56. Duncan JK, Belin MW, Borgstrom M. Assessing progression of keratoconus: novel tomographic determinants. Eye Vis (Lond) 2016 Mar 113:6. 